\title{
INTERNATIONAL ORGANIZATIONS' FLAWS IN RELATIONS TO CLIMATE ALTERATIONS
}

\author{
R. Petkov ${ }^{1 *}$, A. Mindevska ${ }^{2}$ \\ ${ }^{1}$ CUNY, Lehman College, Bronx, NY, USA \\ ${ }^{2}$ CUNY, Brooklyn College, Brooklyn, NY, USA
}

\begin{abstract}
In this paper, we analyze the inability of international organizations to provide an effective response to the global problem of climate change. Specifically, we argue that there appears to be a misfit between the objectives of the international organizations of achieving reduction of greenhouse gases (as whole) and some of the individual members of these organizations. It is evident that some members are unwilling to forgo their internal short term economic benefits in the light of the environment and unwilling to participate in the objectives set by the international organizations to which they belong. To supplement this discussion, we would analyze some of the inherent weaknesses of international organizations that hamper the collective actions against such problems. Specifically, we would discuss problem of universality, unity and sovereignty that obstruct proper collective actions.
\end{abstract}

Key words: international organizations, greenhouse gases

\section{INTRODUCTION}

Hurricane Sandy has proven to be one of the most of devastating storms in the US history. With almost 100 people reported dead, damages ranging in the billions, this storm seems to provide more evidence of the overwhelming destruction from changes associated with global climate change (1). The science behind climate change is fairly easy to understand. As large amounts of greenhouse emissions are emitted, heat is trapped in the atmosphere, and this creates an energy imbalance between how much heat is coming into the earth from the sun and how much is radiated back into space (2). As the result, the global temperature is rising and we have climate change. As many scientists have shown, even though there are many other kinds of climate heat forcers (many of them natural in state), human greenhouse emissions outplace the others by a multiple (3). As the result of these changes, we now observe melting of glaciers, loss of the Artic Sea ice and "more intense and longer droughts", to name a few (4). Previously

*Correspondence to: Rossen Petkov, CUNY,

Lehman College, Bronx, NY,

rossen.petkov@lehman.cuny.edu thought storms with devastating effects, considered to be "once in a life time" storms such as Sandy, are occurring more often. As we get updated of the damaging effects of Sandy and the overwhelming evidences of such global climate changes, we ask ourselves the question how come the international organizations seem to be incapable of marshaling an effective response to this global problem? In this paper, we argue that there appears to be a misfit between the objectives of the international organizations of achieving reduction of greenhouse gases (as whole) and some of the individual members of these organizations. It is evident that some members are unwilling to forgo their internal short term economic benefits in the light of the environment and unwilling to participate in the objectives set by the international organizations to which they belong. To supplement this discussion, we would analyze some of the inherent weaknesses of international organizations that hamper the collective actions against such problems. Specifically, we would discuss problem of universality, unity and sovereignty that obstruct proper collective actions. 
As noted, there appears to be an economic trap among the international organizations (as whole) and the members of international organizations to which they belong. From one point of view, members are interested in the environment. They desire better climate as this would ensure the longevity of the planet and their individual citizens. However, some countries are unwilling to forgo some of their short term economic benefits as with any reduction in the greenhouse gases would require a complete restructuring of their economies. These additional costs are seen as a deterrent for many to push the agenda on the climate control. Some members believe that it would be unfair for economically developed countries to require developing countries to forgo their industrial development in light of the environment. They argue that this would have a long lasting effect on the inequality of members as developing members would not be able to "catch up". On the other side, developed countries believe that if they forgo their greenhouse emissions, this would make them less competitive states. It is clear that each state has an incentive to "pass these economic costs of environment protection on to others, while at the same time benefiting from efforts to reduce the effects" of climate change (5, p.180). That is, even though countries share ecological interest in reduction of greenhouse gas emissions, each country has an economic interest in not reducing the greenhouse gas as the economic costs increase. This social trap is also referred to as the "environmental dilemma" (5, p.180). In order to avoid this scenario, states could work together to share the burden and achieve the benefit of environmental protection via the effective international cooperation. The main premise for the establishment of such international organization is for countries to forgo their short term economic interests for the benefit of longterm ecological interest in climate change. Examples of such organizations are the UNEP and the WMO which conveyed that countries need to take climate control seriously and start reducing their greenhouse gases.

The works of these organizations originated in the early 80 s but with very limited success. It appeared that many countries were on the defense and were deterrent to relax on the demands for compulsory reductions of greenhouse gas emissions. As key argument for such position was the high economic cost. However, after years of negotiations, countries started to relax on some of their differences and discussed the possibility of reductions with the establishment of the Kyoto agreement (5). This agreement called for reduction of emissions by approximately "7-8 per cent by 2012" from their 90 s values (5, p.189). However, in order to force such agreement, it needed to be ratified by developed nations accounting for "at least 55 per cent" of global greenhouse gas emissions (5). Needless to say, such ratification was not made easy as the US withdrew from the agreement as its Congress found it unacceptable for developing countries to be initially exempt from such obligations. Finally, the agreement was made possible by Russia's ratification in 2004 (5).

Even though the premise regarding reduction of greenhouse gas appears to be reasonable, international organizations have not been successful at establishing these objectives for all members as some do not want to ratify such agreements. As some members choose not to work on these issues, this highlights some of the important weaknesses embedded in the international organizations that hamper collective action. These would be discussed in the following paragraphs.

\section{WEAKNESSES OF INTERNATIONAL ORGANIZATIONS}

The first weakness of international organizations is the "problem of universality" (6, p.598). As one of the premise for the creation of international organizations is that "all nations of significant size" must be persuaded to join a "comprehensive international organization" and remain part of it (6, p.598-9). Otherwise, it is a "matter of time before a crisis could spark" $(6$, p.598-9). This is not clearly the case for the purposes of climate control as some of the leading polluters such as the US cannot be persuaded. This clearly weakens the effectiveness of international organizations. In addition, some of the rapidly growing economies such as China, India, and South Africa are not taking on the agreed emission targets. This creates a dilution for the purposes of the agreed reduction plans. It also questions the authority of the international organizations when a member country does not want to ratify a member agreement or the penalties for a member country that has not meet their ratified agreement. It appears that for an international organization to be effective, its rules and regulations must be accepted universally across member states. If this is not the case, it lessens the effectiveness and credibility of the organization. That is, if few significant members do not want to cooperate, 
the organization becomes less effective at dealing with the problem.

The second weakness is the "problem of unity" (6, p.600). In order for an international organization to be effective, all ratified members must agree and be united to its rules and objectives. These objectives should be geared towards the protection of the environment. If we have a split determination regarding a specific problem at hand, it would be almost impossible to come to a resolution. This creates a weakness as countries could not work together if they disagree on principles. In the case of global warming and climate change, there are few countries who have agreed to take actions. However, even these agreed countries are not united in their acceptance and have not lived up to the standards. At end, we have few limited compliant countries that forgo their short term gains in favor of the environment. There are also the others who benefit from the changes made by the compliant countries as the cost of their competitors increase. It is an economic gain/loss game and in the absence of unity, some will not follow the rules as this would make them more competitive. Specifically, for the purposes of climate control, countries that do not have binding emissions targets will have a greater comparative advantage over others. Alternatively, the cost of countries who have agreed on reduction would increase compared to their counterparts. This would make them less competitive in the global market scene. It would not take time for compliant countries "break from their obligations" to international organizations and "push towards more carbonintensive growth paths" than they would otherwise have taken $(5,2006)$.

The third weakness of international organizations is the "problem of sovereignty" $(6$, p. 600). It refers to the nation's ability to govern itself without interference from another nation or organization. In the current political environment, every nation has the last word in its own affairs. To make an effective international organization, it would be necessary for governments to surrender their sovereignty. However, such prospect is not likely as countries fear that such transfer of authority to higher level would lack defense of national interests of individual states. It would benefit some countries in the absence of others.

Another weakness worth mentioning is the "problem of inequality" (6, p. 600). Per this weakness, some members believe that an unfair share is given to some countries (based on their economic development) instead of others. For example, for the Kyoto agreement to be ratified, it needed an agreement of only few developed nations accounting for "at least 55 per cent" of global greenhouse gas emissions (6, p.189). This strict criterion almost completely eliminated the voices of smaller countries and some might argue that this undermines the world rule of law and the concept of sovereignty as decision stays with the few. As a result, the outcome of environment for all, is left to be determined only by the few. Some might argue that such decision undermines the rule of democracy and concept of sovereignty as small member nations would be bound by the decisions made by the few, even if they disagree.

\section{CONCLUSION}

It is clear that after the recent Hurricane Sandy, the climate control debate would become a priority for many states. It is an important discussion and it appears that in order to have a proper resolution, member states needs to give up some of their sovereignty, they needs to act united and universal to reduce their greenhouse emission impacts on the environment. This would entail incurring short term costs to achieve long term environmental goals. However, such plans needs to revaluated in the light of the current economic environment to ensure that each member shares its proper burden of the economic cost and that there is a proper level of fairness. This is, we need to reevaluate the current production functions as the world has changed dramatically since the 90s. As some research has suggested, it is estimated that the rapidly growing economies would overtake the developed countries in the total greenhouse gas emissions $(7,8)$. Therefore, it would be necessary to take into consideration most current data at drafting these future agreements.

\section{REFERENCE}

1. Serna, J., , Hurricane Sandy death toll climbs above 110, N.Y. hardest hit, Los Angelis Times, 2012,

2. http://www.latimes.com/news/nation/nationn ow/la-na-nn-hurricane-sandy-deaths-climb20121103,0,6945430.story, Accessed on November 15, 2012

3. Collins, W. et al, The Physical Science behind Climate Change, Scientific American, 2008, http://www.scientificamerican.com/article.cf $\mathrm{m}$ ?id=science-behind-climate- 
change\&page $=2$, Accessed on November 15, 2012

4. Le Treut, H., et al, Historical Overview of Climate Change. In: Climate Change 2007:

The Physical Science Basis: Contribution of Working Group I to the Fourth Assessment Report of the Intergovernmental Panel on Climate Change, Cambridge University Press, Cambridge, United Kingdom and New York, NY, USA.

http://www.ipcc.ch/publications_and_data/p ublications_and_data_reports.shtml\#.UKbef oc80vY, Accessed on November 15, 2012

5. Solomon, S., et al., Technical Summary In: Climate Change: The Physical Science Basis. Contribution of Working Group I to the Fourth Assessment Report of the Intergovernmental Panel on Climate Change, Cambridge University Press, Cambridge, United Kingdom and New York, NY, USA, 2007, http://www.ipcc.ch/publications_and_data/p ublications_and_data_reports.shtml\#.UKbef oc80vY, Accessed on November 15, 2012

6. Rittberger, V., Zangl, B., International Organization: Polity, Politics and Policies, Chapter 10, pages 180-192, 2006.

7. Magstadt, T., Understanding Politics: Ideas, Institutions, and Issues, Chapter 18, $9^{\text {th }}$ Edition, pages 598-600, 2011.

8. Gregg, et al., China: Emissions pattern of the world leader in $\mathrm{CO} 2$ emissions from fossil fuel consumption and cement production Geophysical Research Letters 35, L08806, 2008, doi:10.1029/2007GL032887, Accessed on November 15, 2012

9. Wen, D., (2009) "CLIMATE CHANGE AND CHINA: Technology, Market and Beyond"

http://www.ifg.org/pdf/occasional_paper6climate_change_and_china.pdf, Accessed on November 15, 2012 